\title{
O CONTEXTO DA EDUCAÇÃO NO MEIO RURAL NO ESTADO DE SÃO PAULO
}

\author{
Jaqueline Daniela Basso \\ Ana Tatiana Staine Cardoso Gobato ${ }^{1}$ \\ Júlia Mazinini Rosa ${ }^{2}$ \\ Universidade Federal de São Carlos (UFSCAR)
}

\section{RESUMO}

Neste texto nos propusemos a realizar uma discussão sobre alguns dados preliminares a respeito da educação no meio rural paulista, entre os anos de 2008 e 2010, por meio da análise de dados disponíveis em fontes como Censo Demográfico, Censos Escolares, Sinopses Estatísticas da Educação Básica, Indicadores Demográficos e Educacionais do Plano de Ações Articuladas, além de informações disponibilizadas pela coordenação do Programa Escola Ativa. O Estado de São Paulo, assim como outros estados brasileiros, apresenta demanda por educação em áreas rurais, porém, a oferta é insuficiente. Mesmo que o Estado apresente algumas das mais altas taxas de urbanização do país, existe a necessidade da escola multisseriada em áreas isoladas. Entretanto, no período estudado, muitas foram fechadas, dando lugar à prática do transporte de alunos para o meio urbano ou ao processo de nucleação, que acontece no Estado desde a década de 1980. Em contrapartida, alguns municípios têm buscado a implementação do Programa Escola Ativa como forma de melhorar os índices educacionais das escolas do campo.

Palavras-chave: educação no campo, escolas no campo, salas multisseriadas, Escola Ativa.

\section{THE CONTEXT OF EDUCATION IN RURAL AREAS IN THE STATE OF SÃO PAULO}

\begin{abstract}
In this article we proposed ourselves to do a short discussion about the education in São Paulo's rural areas, between 2008 and 2010, through information available in sources like the Demographic Census, School Census, Statistics of Basic Education, Educational and Demographic Indicators of the Joint Action Plan, and information provided by Active School Program coordination in this state. The state of Sao Paulo, like other states in Brazil, has demand for education in rural areas, however, the offer is insufficient. There is the need for multigrade schools in isolated areas, however, we noticed that many were closed, giving rise to the practice of transporting children to urban areas or to nucleation, which takes place in the state since 1980s. Conversely, many cities have sought the implementation of Active School Program as a way to improve educational levels in rural areas.
\end{abstract}

Keywords: rural education, multigrade schools, Active School.

\section{Introdução}

O Brasil é um país de tradição agrária desde o período da colonização portuguesa e a primeira forma de exploração econômica empreendida aqui foi o extrativismo vegetal. Posteriormente, Portugal resolveu abandonar o regime de colonização de ocupação e iniciou o povoamento e o cultivo do solo brasileiro, utilizando como mão-de-obra negros e índios escravizados. Esta foi a alternativa encontrada pela burguesia mercantil portuguesa 
que visava o lucro fácil. Assim se desenvolveu a economia açucareira, que se tornou a base econômica predominante da colônia até a primeira metade do século XVIII (RIBEIRO, 2000, p. 19- 20).

As primeiras escolas que foram erguidas no país eram escolas rurais, porém, de acordo com Ribeiro (2000, p. 19-20) a educação escolar, oferecida pela Companhia de Jesus desde 1549, só era conveniente e interessante para a camada dirigente: a pequena nobreza.

No início do século XIX, o eixo econômico brasileiro é transferido da produção açucareira para o a lavoura de café no Centro- Sul do país. A cultura cafeeira que se iniciou no sul do Rio de Janeiro, logo aumentou em direção ao Vale do Paraíba e atingiu o Estado de São Paulo. A cultura do café proporcionou a vinda de imigrantes e a instalação da malha ferroviária no oeste de São Paulo, responsável pelo escoamento da produção agrícola e também base do processo de urbanização e industrialização do interior do país (SAVIANI, 2008, p.187- 188).

$\mathrm{Na}$ sociedade brasileira escravista e de economia agrária exportadora, a educação da mão-de-obra não era valorizada. Até o século XIX, ela aparecia como privilégio para os filhos dos grandes senhores da agricultura (BITTAR, 2007, p. 25). O Brasil ingressou no século XX, com bases societárias rurais, trazendo consigo heranças da escravidão, com uma educação voltada para a elite e uma baixa procura por escolas, quadro que começaria a mudar apenas após 1930 (BITTAR, 2007, p.32).

É histórica a negligência do poder público com relação à educação para a população rural. Contudo, no final do século XX ela volta às pautas governamentais graças às lutas dos movimentos sociais do campo.

Desde as décadas de 1990 e 2000, a denominação educação do campo vem se ampliando para destacar o papel dos sujeitos e a importância da educação em sua formação e desenvolvimento (BRASIL, 2004, p. 36). Kolling, Néry e Mollina (1999, p. 26-29) afirmam que, ao se refletir sobre a educação do campo, há que se pensar naquela voltada para todos os que trabalham no campo e que não são suficientes escolas no campo, mas sim escolas do campo, ou seja, escolas com projetos político-pedagógicos coerentes com as causas, desafios, sonhos, história e cultura do povo trabalhador do campo. Este é o posicionamento do movimento Por uma Educação Básica do Campo. Entretando, outros autores atentam para o fato de que as bases epistemológicas deste posicionamento podem partir da ideia de que o mundo rural é diferente do urbano, como se fossem realidades distintas que não integram uma mesma totalidade (BEZERRA NETO, 2010, p. 152).

O meio rural brasileiro está distante de ser homogêneo e aqueles que o habitam têm interesses bem distintos, quando não antagônicos. Os movimentos sociais relacionam-se fundamentalmente com os assentados da reforma agrária, porém, no campo há trabalhadores remanescentes de quilombolas, pequenos proprietários advindos do processo migratório ao longo dos séculos XIX e XX e outros tantos agricultores que habitam várias regiões brasileiras por décadas e até centenas de anos e não têm relação com os movimentos sociais. Neste contexto, é coerente questionar se a discussão deveria girar em torno de uma educação no campo ou uma educação do campo (BEZERRA NETO, 2010, p. 152).

Se entendermos que o processo educacional deve ocorrer no local em que as pessoas residem, devemos falar de uma educação no campo e aí, não haveria a necessidade de se pensar em uma educação específica para o campo, dado que os conhecimentos produzidos pela humanidade devem ser disponibilizados para toda a sociedade. Se entendermos que deve haver uma educação específica para o campo, teríamos que considerar as 
diversidades apontadas acima e perguntarmos, de que especificidades estamos falando? Partindo deste pressuposto, teríamos que considerar a possibilidade de uma educação para os assentados por programas de reforma agrária, outra para imigrantes, outra para remanescentes de quilombolas e tantas outras quantas são as diferentes realidades do campo. Nesse caso, trabalharíamos apenas com as diversidades e jamais com o que une todos os trabalhadores, que é o pertencer a uma única classe social, a classe dos desprovidos dos meios de produção e por isso, vendedores de força de trabalho, explorados pelo capital (BEZERRA NETO, 2010, p. 152).

Concordamos que as escolas no campo devem oferecer aos seus alunos os saberes acumulados historicamente pela humanidade, nas mesmas condições materiais ofertadas aos alunos das cidades e suas especificidades respeitadas e trabalhadas como também deveria ocorrer nos diferentes espaços urbanos. Partindo deste pressuposto, apresentaremos a seguir uma discussão sobre alguns dados preliminares a respeito da educação no meio rural paulista. Utilizamos como fontes o Censo demográfico de 2010, os Censos Escolares de 2008 a 2010, as Sinopses Estatísticas da Educação Básica de 2008 e 2009, os Indicadores Demográficos e Educacionais do Plano de Ações Articuladas (PAR) do Ministério da Educação e informações disponibilizadas pela coordenação do Programa Escola Ativa no Estado de São Paulo.

\section{As escolas no meio rural no Estado de São Paulo}

Em 2010, de acordo com o Censo Demográfico, 4,12\% da população do Estado de São Paulo era rural. Percentualmente é uma parcela pequena, contudo, em valores absolutos isto representa 1.699 .926 pessoas. Esta população tem direito ao acesso à educação perto de suas moradias, assim como os demais cidadãos paulistas. Porém, no período estudado, como veremos adiante, houve fechamento de escolas e turmas no campo mesmo com um aumento do número de matrículas.

Em 2009 o Censo Escolar indicava que o Estado de São Paulo possuía escolas no campo em 265 de seus 645 municípios, o que representa 40,77\% da totalidade. Em 2010 este número caiu para um total de 263 municípios (http://www.educasensomec.inep.gov.br/basica/censo/default.asp). O gráfico abaixo ilustra a porcentagem de municípios que possuem escolas no campo no Estado de São Paulo no ano de 2010.

Municípios Paulistas com e sem escolas no campo em $2010^{3}$ 


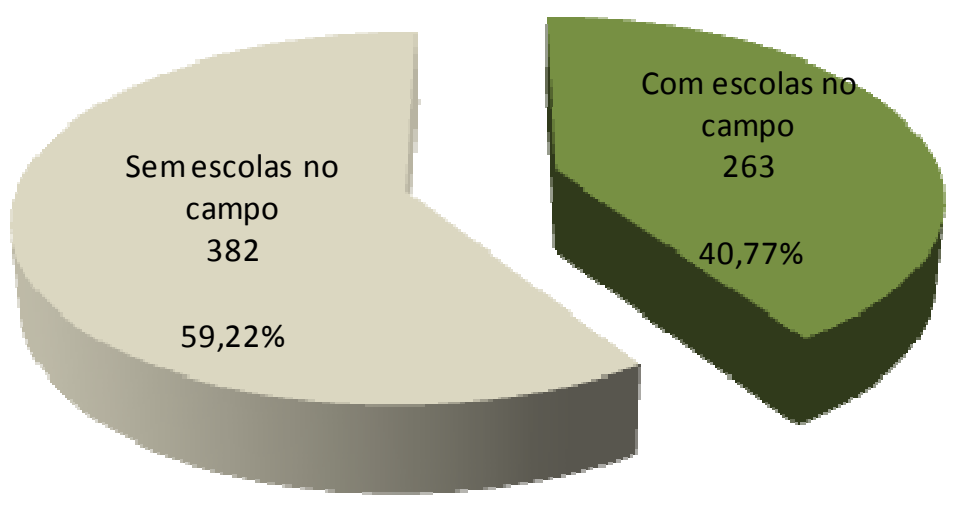

Fonte: Elaborado pelas autoras a partir dos dados do Censo Escolar 2010

Com relação ao número de matrículas, de acordo com os Censos Escolares, em 2009 eram 157.164, considerando-se a Educação Infantil, Ensino Fundamental, Ensino Médio e a Educação de Jovens e Adultos, ou seja, em todos os níveis da educação básica, tanto em período parcial quanto integral. Em 2010 este número caiu para 153.141 (http://www.educasensomec.inep.gov.br/basica/censo/default.asp. Acessado em 10 de janeiro de 2011). A queda do número total de matrículas não indica, necessariamente, que a demanda por escolas nas áreas rurais diminuiu, pois muitos alunos residentes em áreas rurais matriculam-se em escolas urbanas devido à oferta insuficiente de educação básica próximas às suas residências. A Sinopse Estatística da Educação Básica mais recente, disponibilizada pelo Instituto Nacional de Pesquisas Educacionais Anísio Teixeira - INEP indica que, no ano de 2009, de um total de 348.310 alunos provenientes de áreas rurais, 191.146 foram transportados pelo poder público para escolas urbanas.

Os anos iniciais do Ensino Fundamental aparecem como maior demanda das escolas do campo, com um contingente no ano de 2010 de 67.663 alunos ante os 39.966 dos anos finais deste nível e 22.537 do Ensino Médio, como mostra o Censo Escolar 2010 (http://www.educasensomec.inep.gov.br/basica/censo/default.asp).

Esta demanda é atendida tanto pela Rede Estadual quanto pelas Redes Municipais, mas as Redes Municipais são responsáveis pela gestão da maior parte das escolas do meio rural, o que pode ser explicado pela política de municipalização do Ensino Fundamental no país. No ano de 2010, trinta e seis municípios paulistas tinham apenas escolas estaduais no campo, outros noventa e um possuíam somente escolas municipais, enquanto 136 municípios têm suas escolas do campo geridas por ambas as redes (dados do Censo Escolar de 2010). A rede privada, embora esteja presente, é responsável por apenas 179 destas turmas. Outra questão evidente é a ausência da Rede Federal na gestão destas escolas, que conta com apenas uma turma, como mostra o gráfico a seguir:

Número de turmas por rede nas áreas rurais paulistas em 2009 


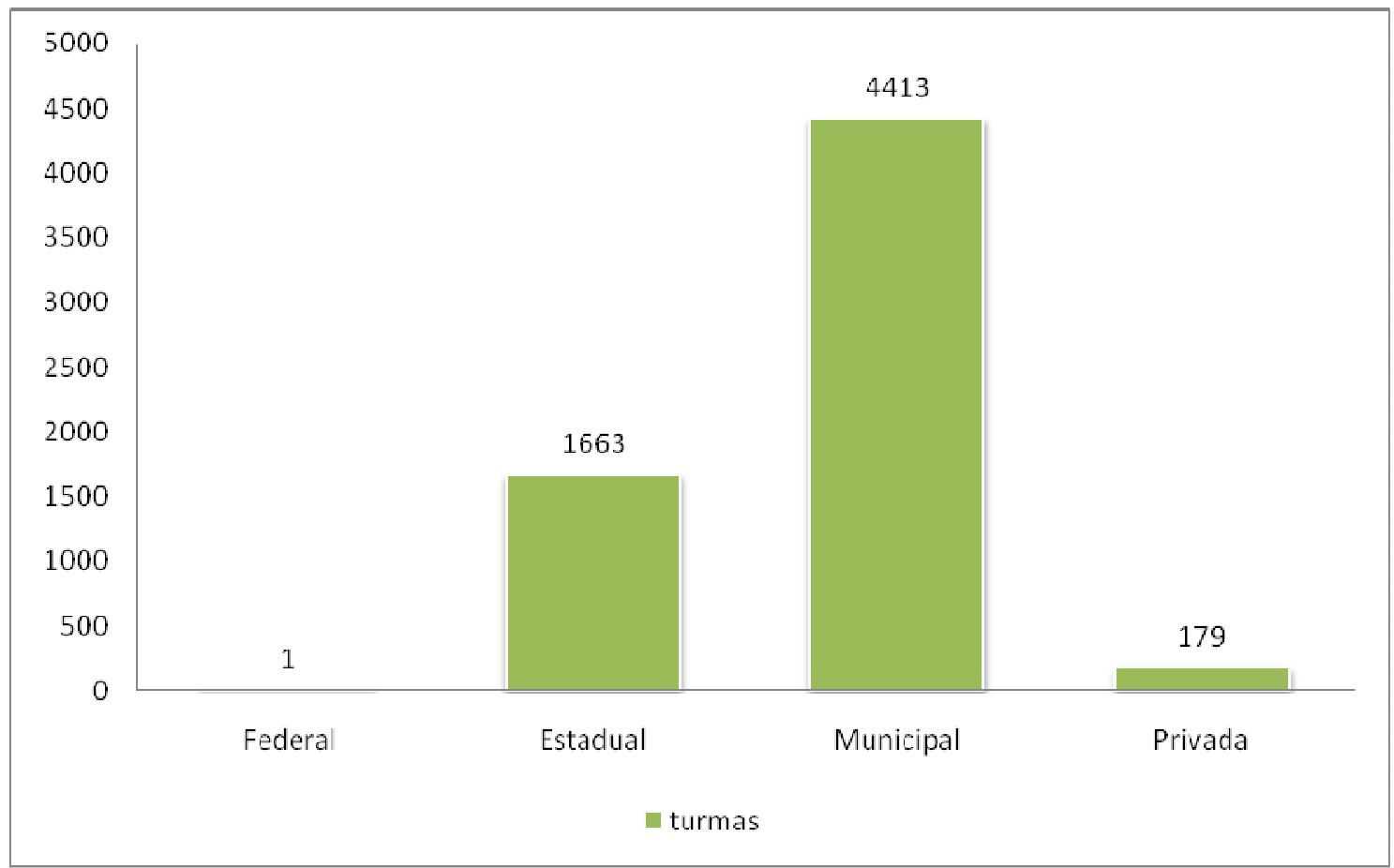

Fonte: Elaborado pelas autoras a partir dos dados da Sinopse Estatística da Educação Básica 2009.

Os indicadores demográficos e educacionais disponíveis no Plano de Ações Articuladas $(\mathrm{PAR})^{4}$ apresentam o número de escolas no campo, sua frequiência de ocorrência nos municípios, além da média de alunos por turma nos diferentes níveis. Estes dados referem-se aos 265 municípios do Estado de São Paulo que possuíam escolas do campo no ano de 2009.

Embora o PAR ofereça informações de grande importância, em seu site na internet, onde é possível acessar estas informações, existe um número significativo de campos que ainda não foram preenchidos pelos comitês municipais de elaboração do plano de ações. É a isso que chamaremos aqui de "falta de informação" no PAR. Por exemplo, no gráfico a seguir, temos o total de escolas no campo sob responsabilidade de Redes Municipais e da Estadual, bem como o número destas escolas presentes em assentamentos da reforma agrária. A maior parte dos municípios pesquisados (98\% na Rede Estadual e 96\% nas Redes Municipais, de um total de 265 municípios com escolas no campo) não apresentou informações sobre a presença ou ausência de escolas em assentamentos. Seria necessário investigar se a falta de informação neste item é por não haver assentamento nos municípios que não disponibilizam esta informação ou por falha dos mesmos municípios no preenchimento dos itens do PAR. Em outros itens do PAR, como número de escolas por etapas de ensino e média de alunos por turma tanto nas Redes Municipais como Estadual, mais de $90 \%$ de municípios não disponibilizam informações. Em cada gráfico apresentado, está explicitada a porcentagem de municípios pesquisados (do total de 265), e da rede a qual pertencem, que preencheram os campos do PAR, portanto, que disponibilizam as informações ilustradas no gráfico.

Total de escolas no campo das Redes Municipais e Estadual no Estado de São PauloDados de 2009 


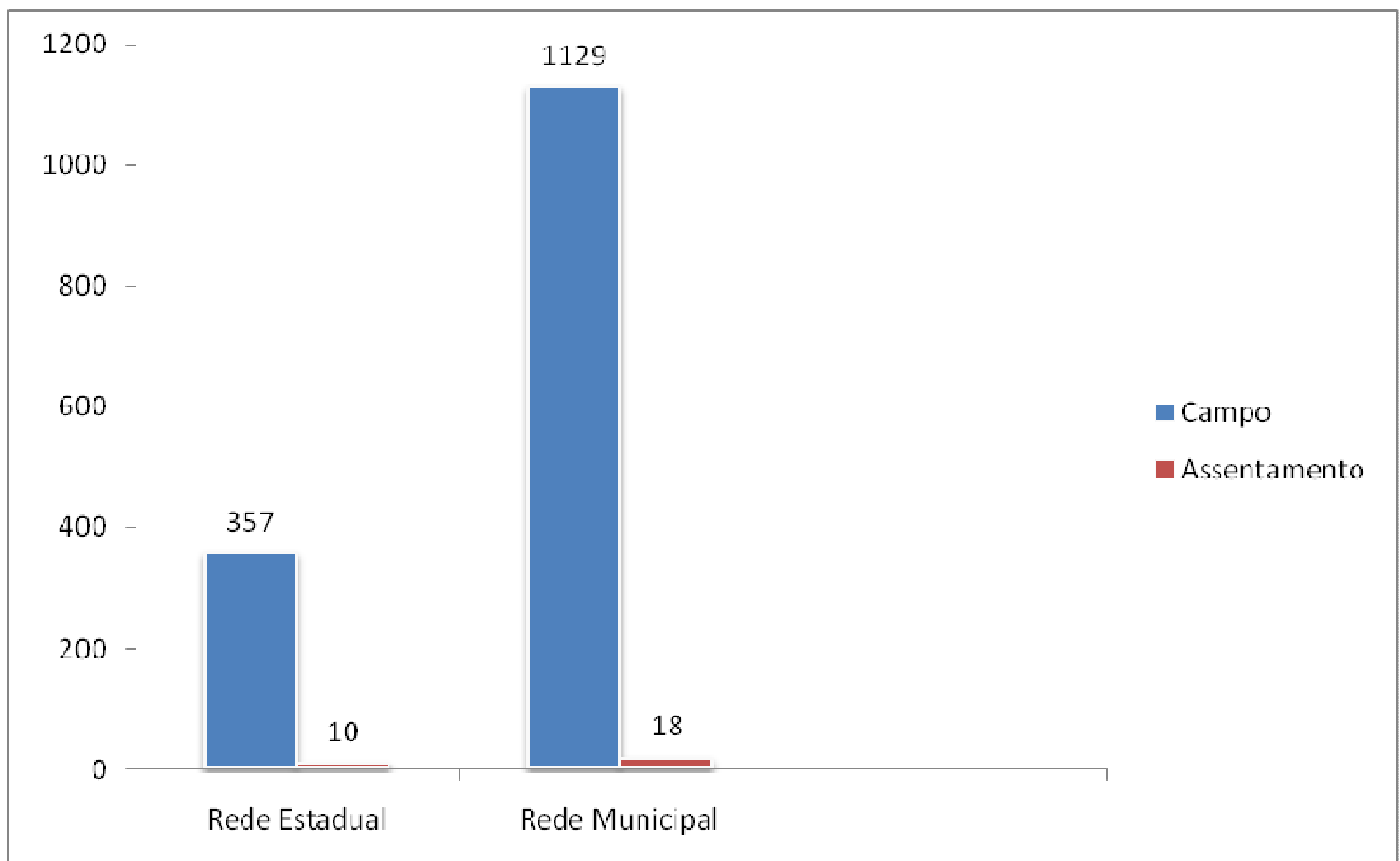

Gráfico elaborado pelas autoras a partir dos Indicadores Demográficos e Educacionais do Plano de Ações Articuladas- PAR.

Os municípios são os responsáveis pela maior parcela do total de escolas no campo em São Paulo, o que corresponde a aproximadamente 75\%. As escolas estaduais são 357, isto é, aproximadamente $24 \%$.

Até o ano de 2009 , das 1.514 escolas no meio rural paulista, vinte e oito (28) faziam parte de assentamentos provenientes da reforma agrária. Contudo, apenas $2 \%$ dos municípios disponibilizam informações sobre escolas em assentamentos na Rede Estadual, e $4 \%$ na Rede Municipal. Cinquenta por cento (50\%) dos municípios pesquisados disponibilizam informação sobre a existência de escolas no meio rural na Rede Estadual e, na Municipal, oitenta e seis por cento (86\%). Estas informações reafirmam a predominância das redes municipais no gerenciamento das escolas do campo.

O gráfico a seguir mostra a frequência da ocorrência de escolas no campo nos municípios paulistas.

Frequência dos municípios (segundo o número de escolas no campo) no Estado de São Paulo- Redes Municipais e Estadual- Dados de 2009 


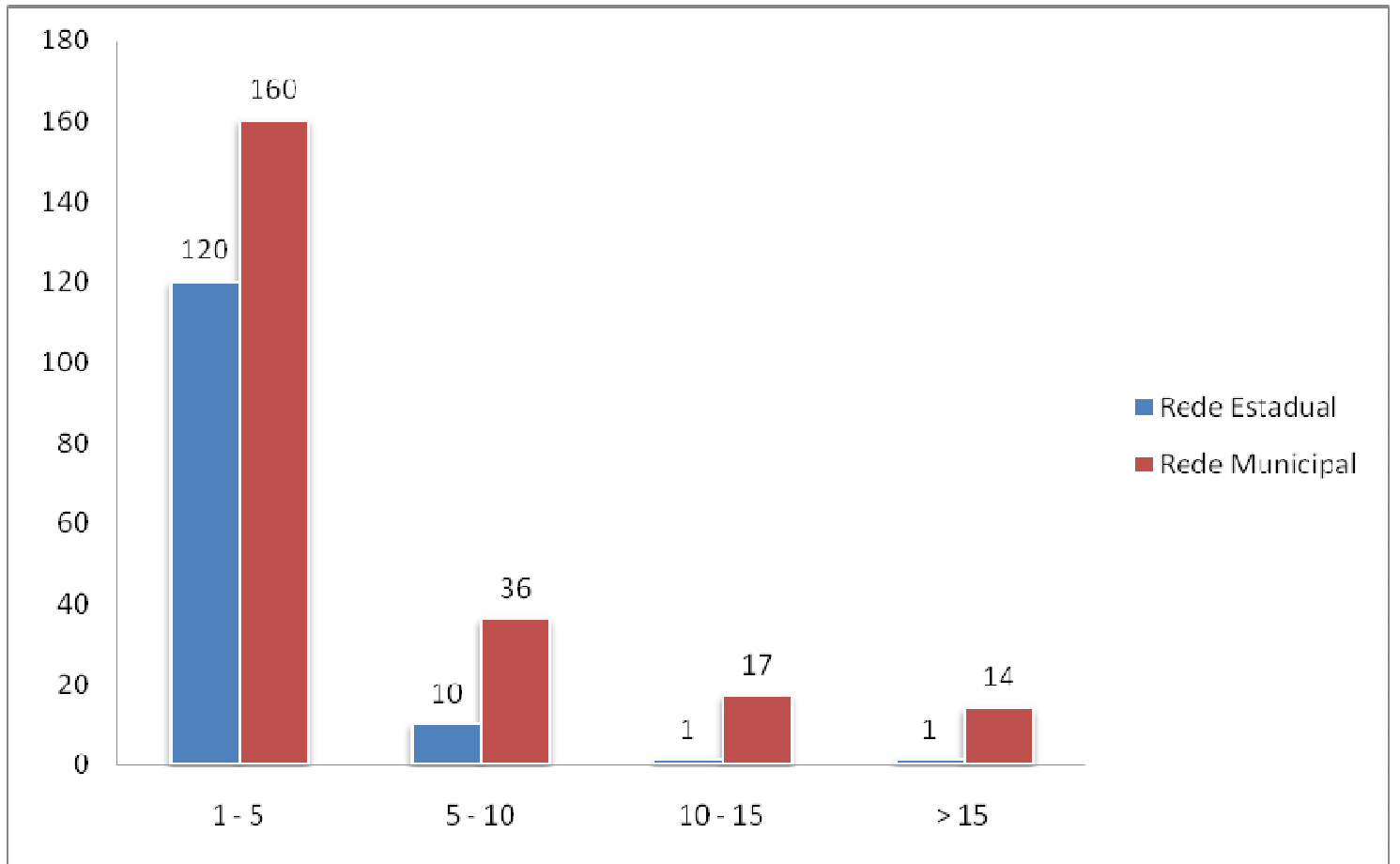

Fonte: Elaborado pelas autoras a partir dos Indicadores Demográficos e Educacionais do Plano de Ações Articuladas- PAR.

A maior parte dos municípios ${ }^{5}$ possui de uma a cinco escolas no meio rural, tanto na Rede Municipal quanto na Rede Estadual. Casos de municípios com mais de quinze escolas no meio rural são raros, entre eles, o município de Cunha se destaca por possuir 48 escolas no campo pertencentes à Rede Estadual e 23 pertencentes à Rede Municipal, Embora não seja um município populoso, aproximadamente $45 \%$ de sua população está no meio rural, totalizando 9703 pessoas, de acordo com o Censo Demográfico de 2010.

Oferta por nível de ensino das escolas no campo das Redes Municipais e Estadual no Estado de São Paulo- Dados de 2009 


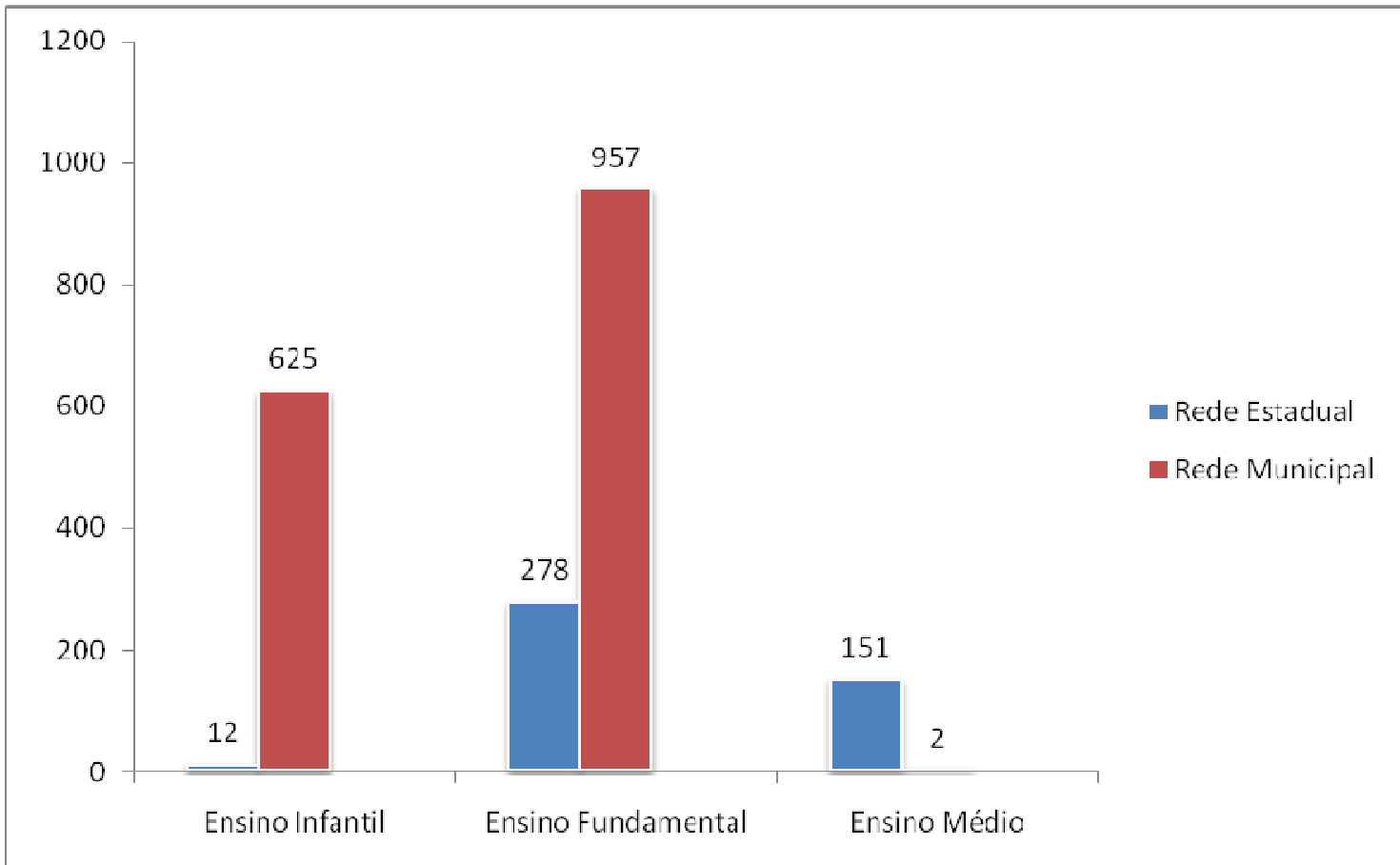

Fonte: Elaborado pela autoras apartir do Indicadores Demográficos e Educacionais do Plano de Ações Articuladas - PAR.

De acordo com o gráfico acima, o Ensino Fundamental é o nível mais ofertado no campo, tanto pela Rede Estadual quanto pelas Municipais. São, no total, 1.235 escolas que oferecem esta etapa de ensino. Já a Educação Infantil, predominantemente, é oferecida pelas redes municipais, sendo pequena a participação do Estado. $\mathrm{O}$ inverso ocorre ao observarmos a oferta do Ensino Médio, já que o Estado é o principal responsável por este nível escolar, enquanto o município disponibiliza apenas duas escolas no campo de nível médio.

O governo estadual é responsável por $98 \%$ da oferta do Ensino Médio no campo, porém, a oferta desta etapa na área rural é muito reduzida, correspondendo a menos de $8 \%$ do total. Isso leva à reflexão sobre as possibilidades de acesso das populações que vivem no campo à educação básica, já que esta não se trata apenas do ensino infantil e fundamental, mas engloba desde a Educação Infantil até a conclusão do Ensino Médio. O que faz a maioria dos alunos residentes do campo ao concluírem o Ensino Fundamental? Interrompem seus estudos ou vão buscar concluí-los nas áreas urbanas? E quando vão buscar a continuação em áreas urbanas, enfrentam horas no deslocamento de suas casas até a escola mais próxima ou deixam o campo em busca de melhores condições de acesso à educação?

Média de alunos por turma nas escolas no campo em cada nível de ensino- Rede EstadualDados de 2009 


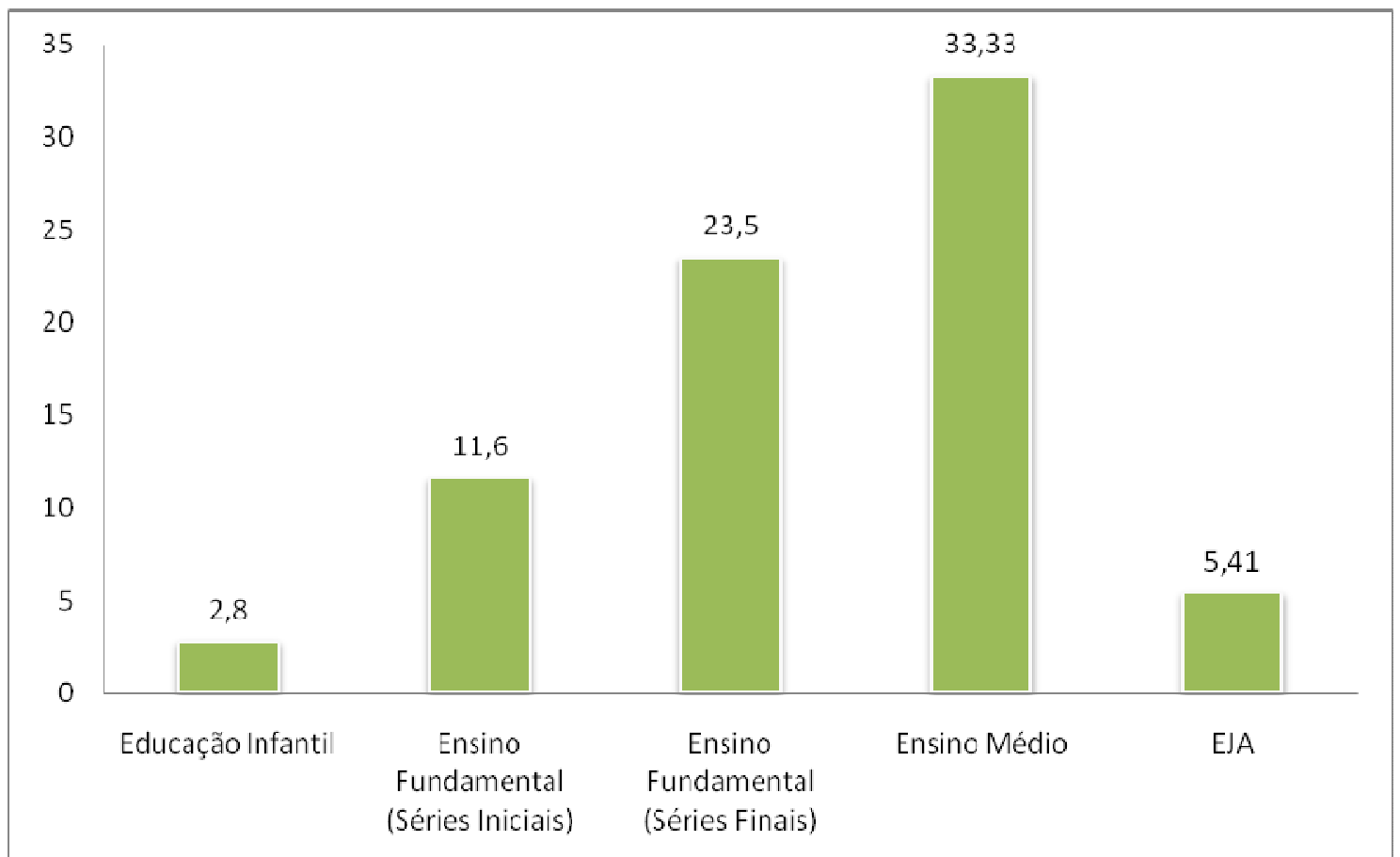

Gráfico elaborado pelas autoras a partir dos Indicadores Demográficos e Educacionais do Plano de Ações Articuladas- PAR.

$\mathrm{Na}$ Rede Estadual, o Ensino Médio tem as turmas mais numerosas: aproximadamente 33 alunos por turma, o que poderia ser consequência da pouca oferta deste nível educacional. As séries finais do Ensino Fundamental possuem uma média de 23 alunos por turma e nas séries iniciais, este número se reduz a aproximadamente 12. A EJA e a Educação Infantil apresentam menos de seis alunos por turma. É importante destacar que, para a Rede Estadual, apenas 4\% dos municípios apresentaram informações sobre a média de alunos por turma na Educação Infantil, 20\% sobre as séries iniciais do Ensino Fundamental, 27\% sobre as séries finais do Ensino Fundamental, 27\% sobre o Ensino Médio e apenas $8 \%$ dos municípios disponibilizaram estas informações sobre a EJA. Média de alunos por turma nas escolas no campo em cada nível de ensino- Rede Municipal- Dados de 2009

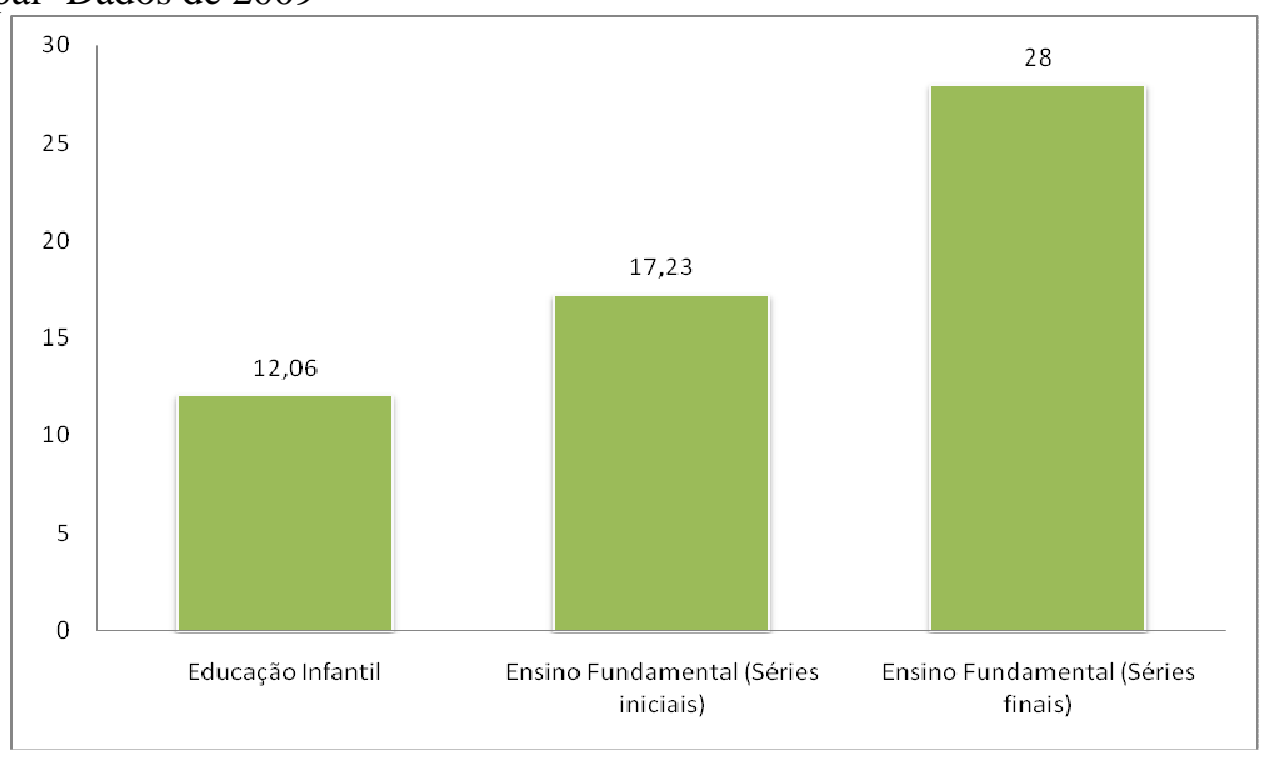


Fonte: Elaborado pelas autoras a partir dos Indicadores Demográficos e Educacionais do Plano de Ações Articuladas- PAR.

Com relação à Rede Municipal, nenhum município pesquisado apresentou informações sobre média de alunos por turma no Ensino Médio e na Educação de Jovens e Adultos. A maior média de alunos por turma, vinte e oito, encontra-se nas séries finais do Ensino Fundamental, sendo que $72 \%$ dos municípios disponibilizaram esta informação. A menor média encontra-se na Educação Infantil, com $68 \%$ dos municípios apresentando informações. As séries iniciais do Ensino Fundamental, as quais frequentemente compõem as escolas multisseriadas, apresentam aproximadamente 17 alunos por turma e $21 \%$ de informações disponíveis.

É possível observar que as escolas do meio rural paulista não possuem turmas muito numerosas. De acordo com Torres (2007, p. 167), uma das recomendações do Banco Mundial aos países em desenvolvimento é de aumentar o número de alunos por sala de aula a fim de baixar custos e utilizar esses recursos em livros didáticos e capacitação docente em serviço. É provável que baixo número de alunos por turma nas escolas no campo contribua para o fechamento destas escolas e priorize o transporte de alunos para a área urbana, em conformidade com a prática de redução de custos com a educação.

Com relação à Educação de Jovens e Adultos, sabemos que é uma medida compensatória para a escolarização daqueles que não a tiveram na idade adequada, por diversos motivos, dentre eles a falta de acesso à educação. Consideramos que o ideal seria que medidas compensatórias não fossem necessárias, porém, enquanto ainda houver demanda por educação de jovens e adultos no campo, é necessário que esta modalidade de ensino seja ofertada. Em 2009 o número de matrículas iniciais nesta modalidade para a área rural do estado de São Paulo foi de 6.409, em ambas as redes, de acordo com o Censo Escolar, porém, o PAR não disponibiliza informações sobre a oferta da EJA no campo.

No contexto educacional explicitado até aqui, persistem as salas multisseriadas, uma forma de organização escolar que não é encontrada no meio urbano, pois é típica de áreas isoladas como áreas rurais.

\section{As salas multisseriadas no Estado de São Paulo}

A sala multisseriada é conceituada por Santos e Menezes (http://www.educabrasil.com.br/eb/dic/dicionario.asp?id=71) como a organização de ensino em que o professor trabalha concomitantemente com várias séries em uma mesma sala de aula. Os autores destacam que este tipo de organização existe predominantemente nas escolas do meio rural, buscando diminuir a evasão escolar e atrair crianças e adolescentes em situação de rua, analfabetas ou com defasagem escolar para que aprendam e prossigam em seus estudos.

Estes autores argumentam que a organização das classes multisseriadas é considerada problemática por algumas pessoas pela dificuldade de trabalho pedagógico com várias séries simultaneamente e pela possibilidade destas condições acarretarem aprendizagens insuficientes. Assim, como as classes multisseriadas são típicas do meio rural brasileiro, acredita-se que a educação do campo esteja sempre colocada em segundo plano, restringindo-se ao ensino das primeiras letras. Porém, mesmo com carências, as salas multisseriadas são consideradas um meio de manter os alunos das áreas rurais na escola (http://www.educabrasil.com.br/eb/dic/dicionario.asp?id=71).

Souza e Santos (2007, p.13) admitem as dificuldades de funcionamento das salas multisseriadas no sistema educacional no país e o constante risco de fechamento destas classes pelas prefeituras por falta de demanda de alunos. "Nesta perspectiva tenta-se 
legitimar a ideia de que para o homem do campo não são necessárias letras, apenas a enxada" (SOUZA E SANTOS, 2007, p. 213).

Ao discutirem sobre a realidade das escolas no campo, Souza e Santos (2007, p. 214), relatam a insuficiência de materiais didáticos e o esforço de professores que trabalham no limiar da infra-estrutura física, salarial e de formação profissional.

As classes multisseriadas nos permitem pensar as contradições que permeiam o campo na atualidade. De um lado, há um número pequeno de crianças em cada série escolar; de outro, os jovens têm que se dirigir às cidades para concluir o Ensino Fundamental e Médio, bem como cursar a Educação Superior. Tal realidade, somada à precariedade política agrícola, contribui para que os jovens demonstrem interesse em migrar para as áreas urbanas (SOUZA E SANTOS, 2007, p. 214).

As salas multisseriadas, muitas vezes, não oferecem condições adequadas de aprendizagem aos alunos e de trabalho aos docentes, contudo, podem ser a única opção ao transporte diário até as escolas urbanas e até mesmo ao abandono da vida escolar. Mesmo em condições precárias de funcionamento, as salas multisseriadas persistem nas áreas rurais em todo o país, e o Estado de São Paulo não foge a esta regra. De acordo com as Sinopses Estatísticas da Educação Básica, disponibilizadas pelo Instituto Nacional de Estudos Educacionais e Pesquisa Anísio Teixeira, em 2009, este Estado ainda contava com 987 turmas multisseriadas no Ensino Fundamental, tanto de oito quanto de nove anos, o que representa aproximadamente $16 \%$ das turmas no campo. Mas este número já diminuiu se comparado ao ano de 2008, em que havia 1745 destas turmas em todo o Estado.

Embora tenha diminuído o número de salas multisseriadas, não significa necessariamente que os alunos que as frequentavam deixaram as escolas ou foram transportados para as cidades. Se compararmos os Censos Escolares 2008 e 2009, perceberemos que o número de matrículas no Ensino Fundamental em escolas no campo aumentou de um ano para outro: em 2008 eram 110.193 alunos, já em 2009 este número subiu para 113.170. É possível que a diminuição do número de salas seja explicada pela política de nucleação ou agrupamento das escolas rurais que ocorre há mais de trinta anos em São Paulo.

No ano de 1989, o Estado de São Paulo, representado pela Secretaria de Educação em articulação com a FDE - Fundação para o Desenvolvimento da Educação começou o agrupamento das escolas rurais em torno de novos núcleos, almejando o fim da multisseriação e melhores condições de ensino no campo. Agrupar as turmas foi a alternativa encontrada pelo governo paulista para superar o "modelo historicamente constituído das escolas unidocentes e multisseriadas, isoladas e de emergência ${ }^{6}$, que vigorou por trinta anos, desde a criação destas últimas em 1957 (Lei 3.783), consideradas padrão típico de oferta de ensino à população rural" (VASCONCELLOS, 1993, p. 66).

$\mathrm{O}$ agrupamento não é exclusividade do Brasil, ele ocorre de modo semelhante em outros países como Líbano, Irã, Costa Rica, Estados Unidos e Índia (VASCONCELLOS, 1993, p. 66-70). Em todos eles sempre esteve presente a discussão dos ganhos trazidos pelas mudanças geradas pela nucleação, uma vez que envolvem transformações profundas na distribuição física das escolas, na redistribuição de verbas governamentais e consecutivamente, nas condições materiais de acesso da população rural às escolas.

Como nos mostra o autor, isso se deve ao fato de que, ao realizar a nucleação de escolas rurais, pequenas vilas e comunidades deixavam de possuir em seu interior não apenas uma escola em seu sentido físico, mas também em muitos casos, os laços comunitários que esta escola e o professor que nela trabalhava possuíam com a 
comunidade em que estava inserida. Após seu fechamento, os moradores destes locais precisavam então enviar seus filhos para a escola nucleada mais próxima a suas residências, muitas vezes longe o bastante para necessitarem de ônibus escolares para transportá-los a esta escola sede.

Referindo-se a questão do financiamento da educação, mais especificamente no que concerne ao transporte escolar que se fez necessário com a nucleação das escolas, Lord (2008) nos chama a atenção para o fato de que esta nova organização escolar, ao mesmo tempo em que possibilitou modificações que possuíam a finalidade de aumentar a qualidade do ensino oferecido, fez com que a escola se distanciasse das famílias dos alunos, principalmente daquelas famílias residentes em regiões mais distantes e com menos condições de acesso e serviços públicos (LORD, 2008, p. 132-133.).

A eficiência dos governos públicos no financiamento do transporte escolar é de fundamental relevância quando o assunto é o acesso e a permanência na escola dos alunos moradores das áreas rurais. Esse transporte escolar que pode ser da residência do aluno para uma escola no campo, ou então da residência do aluno para uma escola urbana é considerado pelo autor como um dos fatores que contribui, quando feito com a qualidade necessária, para a conclusão dos estudos dos alunos oriundos do campo (LORD, 2008).

Entretanto, Lord (2008) afirma que, quando as distâncias entre a residência dos alunos e a escola na qual estuda é muito longa, como nos casos das escolas nucleadas, o próprio transporte escolar se transforma num fator de impasse para a continuação dos estudos, sendo muitas vezes o motivo da desistência e evasão dos alunos da escola. Com a nucleação das escolas multisseriadas, a importância do transporte escolar é tal que, quando sua realização é feita de forma insuficiente para o atendimento de todas as crianças e jovens, este se torna mais um elemento que intensifica a exclusão escolar de alguns alunos.

Em São Paulo, rapidamente, o processo de agrupamento gerou a redução do número de escolas multisseriadas. Em 1988 eram 9.653 unidades, enquanto dois anos depois, em 1990 este número já havia sido reduzido em 62\%, totalizando 3.684 unidades. Contudo, o processo de nucleação não teve aceitação unânime, a população atingida tinha dificuldade em chegar ao consenso de onde seria a nova escola nucleada, uma vez que as pequenas escolas estavam mais perto do trabalho dos pais, além do receio existente quanto à qualidade da nova escola e segurança do transporte oferecido para o deslocamento dos alunos (VASCONCELLOS, 1993, p. 66-68).

Assim, percebemos que o processo de agrupamento surgiu como tentativa do governo de reduzir o número de salas multisseriadas, além de tentar melhorar a qualidade da educação em áreas rurais paulistas. Porém, trouxe para aqueles que residem no campo um novo impasse: o distanciamento da escola e a consequente necessidade de sujeitar seus filhos diariamente ao transporte, quase sempre em condições inadequadas.

Ao longo da história, portanto, tem-se buscado erradicar as salas multisseriadas no meio rural paulista, entretanto, as Sinopses Estatísticas nos mostraram que elas continuam existindo. Para auxiliar o trabalho docente e melhorar as condições de aprendizagem nestas salas, a partir de 2007, vários municípios do Estado de São Paulo aderiram ao Programa Escola Ativa e a Rede Estadual fez sua adesão em 2010.

\section{O Programa Escola Ativa como política pública para escolas ${ }^{7}$ multisseriadas}

Gonçalves (2009), em sua tese de doutoramento, realiza uma avaliação do Programa Escola Ativa, que conceitua da seguinte maneira: 
O programa Escola Ativa (PEA) foi implementado no Brasil a partir de 1997 no marco de um convênio com o Banco Mundial, com o objetivo de melhorar o rendimento dos alunos de classes multisseriadas rurais. $\mathrm{O}$ PEA tem seu foco na formação de professores e na melhoria da infraestrutura das escolas, e propõe amplas mudanças na organização do trabalho docente, constituindo-se no único programa voltado especificamente para as classes multisseriadas no Brasil (GONÇALVES, 2009, p. 5).

A metodologia do Programa Escola Ativa parte do pressuposto de que o aluno é um sujeito ativo e participante do processo de ensino-aprendizagem, que deve estar associado à sua vida e ao seu cotidiano. O Programa tem como princípio o fato de que não se pode trabalhar com a multissérie do mesmo modo que se trabalha com a turma unisseriada, portanto, propõe formas alternativas de organização e funcionamento de turmas multisseriadas (BRASIL, 2010 p. 30).

As estratégias do Programa Escola Ativa com relação ao trabalho pedagógico compreendem a organização dos estudantes em grupo, com o auxílio de um monitor por grupo; a ressignificação do trabalho do professor, que deve coordenar e orientar as atividades dos estudantes em cada grupo e reduzir as aulas expositivas; a articulação entre alunos e professores dos elementos do Programa (Cadernos de Ensino Aprendizagem, Colegiado Estudantil, Cantinhos de Aprendizagem e Comunidade) (BRASIL, 2010, p. 30 E 31).

Os municípios paulistas iniciaram sua adesão ao Programa em 2007, e, até o ano de 2010, 203 deles já o haviam implantado, de acordo com dados fornecidos pela coordenação do programa no Estado. É importante ressaltar que esta adesão é facultativa e ocorre por meio do PAR. Isso pode indicar certa preocupação dos municípios que ainda possuem salas multisseriadas em minimizar os prejuízos no ensino e aprendizagem que elas possam acarretar.

Ao avaliar o Programa Escola Ativa, Gonçalves (2009, p.141), ressalta que ele possui aspectos positivos, pois é uma forma de valorizar a escola multisseriada, na medida em que afasta a nucleação como principal alternativa para a educação do campo e, pelo fato de que vem melhorando a infra-estrutura em algumas escolas do campo. Porém, existem aspectos negativos que se traduzem na forma antidemocrática com que acontece a implementação do programa, ou seja, nas relações verticais de poder. Essa falta de abertura, traço marcante em todos os âmbitos do programa, desde a implementação até a sua avaliação, faz com que o programa se distancie das propostas de educação do campo defendidas pelos movimentos sociais (GONÇALVES, 2009, p. 141). Além disso, o Programa Escola Ativa melhorou as condições materiais de trabalho docente, porém, não o suficiente para garantir condições adequadas de aprendizagem a todos os alunos e de trabalho aos professores, que tem reduzida autonomia e condições laborais precárias com a intensificação e extensão da jornada (2009, p. 5- 6).

Embora os objetivos do Programa Escola ativa sejam a autonomia e a participação, para Gonçalves (2009, p. 76), o Programa se enquadra em uma linha pedagógica liberal, que está mais comprometida em servir ao sistema produtivo e reproduzir as relações sociais vigentes do que educar para a emancipação e para a crítica.

\section{Considerações Finais}

A escola brasileira surgiu no meio rural, porém a população que nele habita ainda tem restrita possibilidade de acesso à educação. Devido a reivindicações dos movimentos 
sociais do campo, esta educação passou a denominar-se do campo a partir da década de 1990, o que suscitou discussões acerca do que seria a educação do e no campo. Acreditamos que a educação que deva ocorrer é uma educação no campo, ou seja, uma educação no meio rural que ofereça as mesmas condições de acesso à educação a todos aqueles que compõem a classe dos trabalhadores, sejam eles urbanos ou rurais.

Ao analisarmos os indicadores disponíveis sobre a educação no meio rural paulista, confirmamos a dificuldade de acesso à educação neste meio, pois escolas são fechadas enquanto matrículas aumentam. Com relação à oferta dos níveis de ensino, também é insuficiente, visto que na maioria dos casos se resume ao Ensino Fundamental. Desta maneira, aqueles que querem prosseguir nos estudos muito provavelmente precisarão se deslocar até as cidades.

No limiar entre aumentar a oferta de educação e oferecê-la com qualidade questionável, estão as classes multisseriadas. Embora o Estado de São Paulo tenha implantado o agrupamento das escolas rurais há mais de trinta anos, as multisséries ainda representam $16 \%$ do total de turmas rurais. Para minimizar as possíveis perdas na aprendizagem dos alunos que frequentam estas turmas, o Governo Federal implementou o programa Escola Ativa, única política pública no país voltada para as turmas multisseriadas no campo.

É possível que o Programa Escola Ativa contribua para melhorar as condições de trabalho docente e infraestrutura física nas multisséries. Contudo, ainda apresenta relações verticais de poder na sua implementação, resquícios de sua vertente liberal, nem sempre declarada, e que limita a autonomia docente.

Para finalizar, não pretendemos aqui, reduzir a educação no meio rural paulista a números, mas, a partir deles, começar a elucidar o contexto em que ela acontece e gerar subsídios a futuras pesquisas.

\section{Referências}

BEZERRA NETO, Luiz. Educação do campo ou educação no campo? Revista HISTEDBR On-line, Campinas, n. 38, p. 150- 168, junho de 2010. Disponível em: <http://www.histedbr.fae.unicamp.br/revista/edicoes/38/index.html>. Acesso em $10 \mathrm{de}$ janeiro de 2011.

BITTAR, Marisa. Universidade, Pesquisa Educacional e Educação Básica. In: BITTAR, Marisa; LOPES, Roseli Esquerdo (orgs.). Estudos em fundamentos da educação. São Carlos, SP: Pedro e João Editores, 2007. pp: 21- 49.

BRASIL, INEP. Censo Escolar 2010: Disponível em: <http://www.educasensomec.inep.gov.br/basica/censo/default.asp>. Acesso em 10 de janeiro de 2011.

BRASIL, INEP. Sinopses Estatísticas da Educação Básica de 2008 e 2009. Disponíveis em <http://www.inep.gov.br/basica/censo/Escolar/sinopse/sinopse.asp> Acesso em $20 \mathrm{de}$ março de 2011.

BRASIL, Ministério da Educação e Cultura: Plano de Ações Articuladas. Apresentação. Disponível em: <http://simec.mec.gov.br/cte/relatoriopublico/principal.php> Acesso em: 25 de abril de 2011. 
BRASIL, Ministério da Educação e Cultura: Plano de Ações Articuladas. Indicadores Demográficos e Educacionais. Disponíveis <http://simec.mec.gov.br/cte/relatoriopublico/principal.php> Acesso em 09 de março de 2011.

BRASIL. Ministério da Educação e Cultura. Escola Ativa: projeto base. Brasília: MEC; FNDE; SECAD, 2010, 48p.

BRASIL. Ministério da Educação e Cultura. Secretaria de Educação Média e Tecnológica. Grupo Permanente de Trabalho de Educação do Campo. Referências para uma política nacional de educação do campo: Caderno de Subsídios. Coordenação: Marise Nogueira Ramos, Telma Maria Moreira, Clarice Aparecida dos Santos. Brasília: 2004, 48 p. Disponível em <http://www.red.ler.org/referencias.educacao.campo.pdf> Acesso em 08 de março de 2011.

GONÇALVES, Gustavo Bruno Bicalho. Programa Escola Ativa: educação do campo e trabalho docente. Rio de Janeiro, 2009. 208 f. Tese (Doutorado em Políticas Públicas). Programa de Pós-Graduação em Políticas Públicas e Formação Humana, Universidade do Estado do Rio de Janeiro, Rio de Janeiro, 2009.

IBGE. Censo Demográfico 2010. Disponível em <http://www.ibge.gov.br/censo2010/primeiros_dados_divulgados/index.php?uf=35> Acesso em 22 de janeiro de 2011.

LORD, Lucio. Financiamento do transporte escolar e a questão das zonas rurais no Brasil. Revista da Faculdade de Educação. Universidade do Estado de Mato Grosso. Ano VI, n09. P.129-140. Cáceres-MT. 2008.

KOLLING, Edgar Jorge; NÉRY, Israel José; MOLINA, Mônica. Castagna. Por uma educação básica do campo. Brasília: Fundação Universidade de Brasília, 1999. Vol. I. $95 \mathrm{p}$.

MENEZES, Ebenezer Takuno de; SANTOS, Thais Helena dos. Classes multisseriadas (verbete). Dicionário Interativo da Educação Brasileira - EducaBrasil. São Paulo: Midiamix $\quad 2002.2$ Disponível em: <http://www.educabrasil.com.br/eb/dic/dicionario.asp?id=71> Acesso em 8 de abril de 2011.

RIBEIRO, Maria Luisa Santos. História da educação brasileira. $16^{\mathrm{a}}$ ed. Campinas, SP: Autores Associados, 2000. 207 p.

SAVIANI, Dermeval. As ideias pedagógicas do Brasil entre 1932 e 1969: predomínio da pedagogia nova. In: História das Ideias Pedagógicas no Brasil. Campinas, SP: Autores Associados, 2008. pp. 185- 193.

SOUZA, Maria Antônia de; SANTOS, Fernando Henrique Tisque dos. Educação do campo: prática do professor em turma multisseriada. Diálogo Educacional, Curitiba, v. 7, n. 22, p. 211-227, set./dez. 2007. Disponível em: <http://www2.pucpr.br/reol/index.php/DIALOGO?dd1=1584\&dd99=view > Acesso em 14 de abril de 2011. 
TORRES, Rosa María. Melhorar a qualidade da educação básica? As estratégias do Banco Mundial. In: TOMMASI, Lívia; WARDE, Miriam Jorge; HADDAD, Sérgio. O Banco Mundial e as Políticas Públicas Educacionais. São Paulo: Cortez Editora. $5^{a}$ edição. 2007.

VASCONCELlOS, Eduardo A. Agrupamento de Escolas Rurais: alternativa para o impasse da educação rural? Cadernos de Pesquisa. São Paulo, n. 86, p. 65- 73, agosto de 1993. Disponível em <http://www.fcc.org.br/pesquisa/publicacoes/cp/arquivos/894.pdf> Acesso em 16 de abril de 2011.

\footnotetext{
${ }^{1}$ Mestrandas do Programa de Pós- Graduação em Educação da Universidade Federal de São CarlosUFSCar, sob a orientação do Prof. Dr. Luiz Bezerra Neto.

${ }^{2}$ Mestranda do Programa de Pós- Graduação em Educação da Universidade Federal de São CarlosUFSCar, sob a orientação da Prof ${ }^{a}$ Dra. Maria Cristina dos Santos Bezerra.

${ }^{3}$ Todos os gráficos apresentados foram feitos no programa Microsoft Excel 2007 a partir de dados numéricos disponíveis nas fontes Censos Demográficos e Escolares, Sinopses Estatísticas da Educação Básica e Plano de Ações Articuladas (PAR).

${ }^{4}$ Em abril de 2007 o Plano de Desenvolvimento da Educação- PDE do Ministério da Educação e CulturaMEC disponibilizou aos Estados, Distrito Federal e municípios instrumentos com objetivo proclamado de realizar avaliação e implementação de políticas públicas que visam melhorar a qualidade da educação, principalmente da Educação Básica Pública. Um dos programas estratégicos do PDE é o Plano de Metas Compromisso Todos Pela Educação que representa, segundo o MEC, um novo modo de cooperação entre as esferas governamentais, que busca reparar a atuação dos entes federados sem que estes percam sua autonomia no que se refere a decisões políticas, ações técnicas e atendimento à demanda escolar em busca da melhoria dos indicadores educacionais. Ao aderirem ao Plano de Metas Compromisso Todos pela Educação, os estados e municípios devem elaborar seus Planos de Ações Articuladas- PAR, o primeiro passo para isto é a realização de um diagnóstico da realidade educacional local, a partir do qual, serão desenvolvidas as ações educacionais. Os resultados destes diagnósticos são os "Indicadores Demográficos e Educacionais" que usaremos como fonte para este trabalho (http://portal.mec.gov.br/index.php?option=com_content\&view=article\&id=159\&Itemid=369).

${ }^{5}$ É importante ressaltar que o PAR discrimina os dados que serviram de base para o gráfico acima por rede gestora e não por município, isto é, um mesmo município pode possuir tanto escolas pertencentes à Rede Estadual quanto pertencentes à Rede Municipal. Podemos observar, por exemplo, que, dos 160 municípios que possuem de uma a cinco escolas no campo geridas pelas Redes Municipais, muitos podem ter sido contabilizados entre os 120 que possuem de uma a cinco escolas no campo geridas pela Rede Estadual.

${ }^{6} \mathrm{O}$ decreto 29.499 , de 5 de janeiro de 1989, que regulou a implantação do agrupamento das escolas rurais no Estado de São Paulo, determinou que todas escolas de uma sala só se transformassem em escolas de emergência, e estas, por conseguinte poderiam se agrupar em conjuntos de duas a sete salas, passando a chamar-se Escola Estadual de Primeiro Grau Rural- EEPG (R) (VASCONCELLOS, 1993, p. 66).

${ }^{7}$ No projeto base do Programa Escola Ativa os termos classe multisseriada e escola multisseriada são empregados como sinônimos, contudo, nem sempre o são. É comum que uma única sala multisseriada seja a própria escola, mas pode ocorrer que em uma escola haja mais de uma sala multisseriada.
}

Recebido em:18/05/2011

Aprovado em: 15/06/11 